\title{
Gradient structure produces superior dynamic shear properties
}

\section{Xiangde Bian, Fuping Yuan, Yuntian Zhu \& Xiaolei Wu}

To cite this article: Xiangde Bian, Fuping Yuan, Yuntian Zhu \& Xiaolei Wu (2017): Gradient structure produces superior dynamic shear properties, Materials Research Letters, DOI: 10.1080/21663831.2017.1334715

To link to this article: http://dx.doi.org/10.1080/21663831.2017.1334715

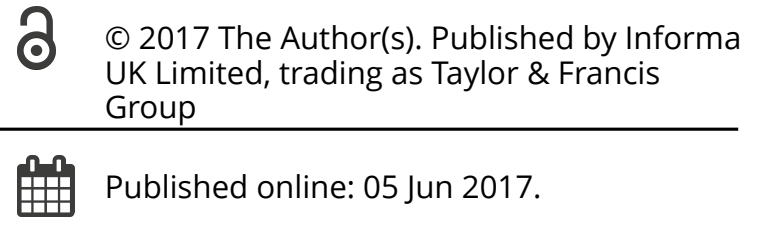

Submit your article to this journal

Q View related articles $₫$

View Crossmark data $₫$ 


\title{
Gradient structure produces superior dynamic shear properties
}

\author{
Xiangde Bian ${ }^{a, b}$, Fuping Yuan ${ }^{a, b}$, Yuntian Zhu ${ }^{c, d}$ and Xiaolei Wu ${ }^{a, b}$ \\ aState Key Laboratory of Nonlinear Mechanics, Institute of Mechanics, Chinese Academy of Sciences, Beijing, People's Republic of China; \\ ${ }^{b}$ School of Engineering Science, University of Chinese Academy of Sciences, Beijing, People's Republic of China; ${ }^{\circ}$ Department of Materials \\ Science and Engineering, North Carolina State University, Raleigh, NC, USA; ${ }^{\mathrm{d}}$ Nano Structural Materials Center, School of Materials Science and \\ Engineering, Nanjing University of Science and Technology, Nanjing, People's Republic of China
}

\begin{abstract}
We report that gradient-structured twinning-induced plasticity steels have much superior dynamic shear properties over homogeneous nanostructured (NS) counterparts. The gradient structure was found to delay the nucleation of adiabatic shear bands (ASBs) at the NS surface layers and to reduce the propagation speed of ASB by an order of magnitude as compared with homogeneous NS materials. The conventional maximum stress criterion on ASB initiation for homogeneous materials is found not valid for gradient structure. These findings may provide insights for designing impact-tolerant gradient structures with excellent dynamic properties.
\end{abstract}
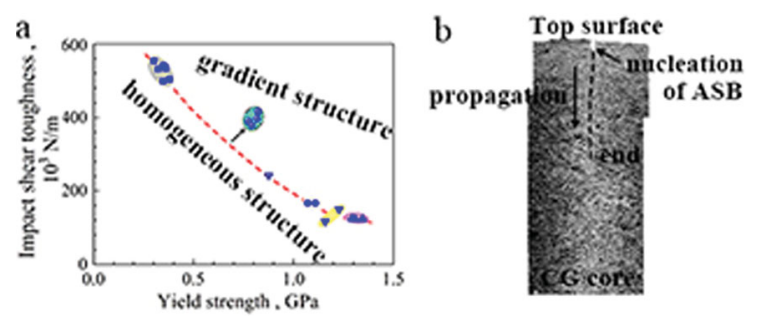

\section{IMPACT STATEMENT}

Gradient structures were found to produce superior dynamic shear properties that are not accessible to their homogeneous counterparts due to the suppression of nucleation and propagation of adiabatic shear bands.

\section{ARTICLE HISTORY}

Received 6 April 2017

\section{KEYWORDS}

Gradient structure; dynamic shear response; adiabatic shear band; ductility; Hopkinson bar
Metals and alloys with both high strength and ductility have been pursued by scientists and engineers for several decades [1-11]. Gradient structure, where the grain/subgrain-structure size changes gradually from the surface to the interior [12-19], shows superior ductility-strength combination under quasi-static tensile loading, which was attributed to either mechanically driven grain growth for unstable nanostructured (NS) surface layer [15] or extra strain hardening by the presence of strain gradient together with the stress state change for the mechanically stable gradient structure [13,17]. Back stress hardening has been reported to play a significant role in the mechanical behavior and properties of gradient structures [12], similar to what occurs in other heterogeneous structures $[10,20,21]$.
The flow behaviors of structural materials are strongly affected by the applied strain rate [22-25]. At high strain rates the adiabatic heating results in substantial temperature rise, thermal softening and formation of adiabatic shear band (ASB), which triggers fracture [25-29]. The dynamic shear response and evolution mechanisms of ASB in homogeneous materials with coarse grains (CG), ultra-fine grains (UFG) and nanograins (NG) have been extensively investigated [25-36]. Typically, CG materials have low yield strength, high critical strain for onset of ASB and high impact toughness, while UFG and NG materials possess high yield strength, low uniform strain and low impact toughness. In other words, there exists a strength-toughness trade-off for homogeneous metals under dynamic shear loading. A question arises on

CONTACT Fuping Yuan fpyuan@Inm.imech.ac.cn $\Theta$ State Key Laboratory of Nonlinear Mechanics, Institute of Mechanics, Chinese Academy of Sciences, 15 Beisihuan West Road, Beijing 100190, People's Republic of China; Xiaolei Wu xlwu@imech.ac.cn State Key Laboratory of Nonlinear Mechanics, Institute of Mechanics, Chinese Academy of Sciences, 15 Beisihuan West Road, Beijing 100190, People's Republic of China; School of Engineering Science, University of Chinese Academy of Sciences, 19A Yuquan Road, Beijing 100049, People's Republic of China 

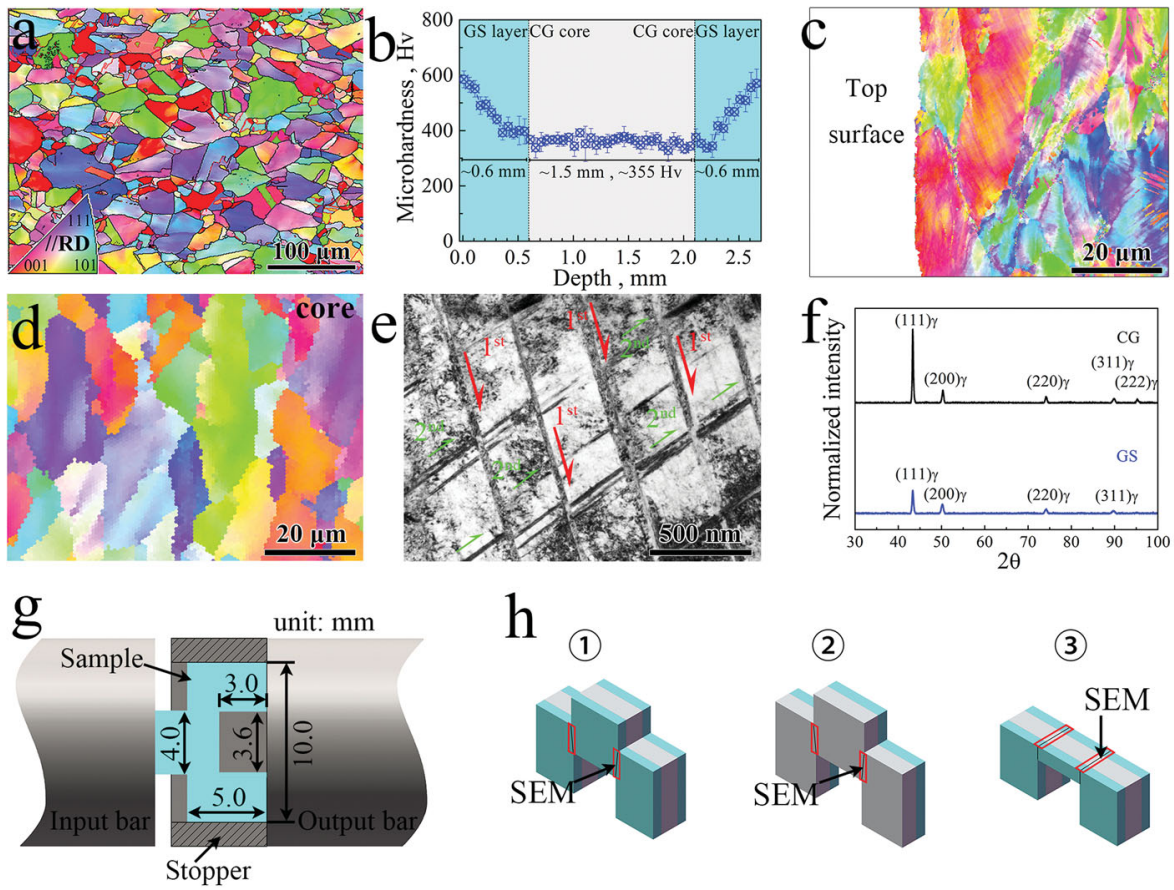

$\mathrm{h}$

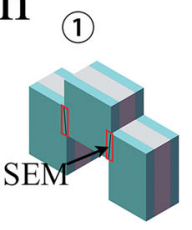

(2)

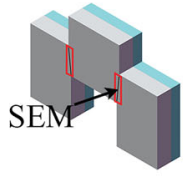

(3)

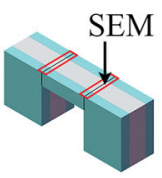

Figure 1. (a) EBSD image for the untreated CG sample; (b) Vickers microhardness along the depth in a sample processed by SMAT for 20 min; (c) EBSD image for the treated surface; (d) EBSD image for the center part; (e) TEM micrograph at the depth of $50 \mu$ m; (f) X-ray diffraction patterns; $(\mathrm{g})$ the set-up of Hopkinson bar experiments with hat-shaped specimens; (h) schematics of sample extractions for microstructural examination.

if the superior strength-ductility combination of gradient structures under quasi-static strain rates can translate into superior strength-toughness under high strain rates.

Here, we report that the gradient-structured metals can produce extraordinary strength-toughness combination that is not accessible to homogeneous materials. The underlying mechanisms were revealed and will be discussed.

Hot-rolled twinning-induced plasticity (TWIP) steel with (wt\%) $0.6 \mathrm{C}, 23 \mathrm{Mn}, 0.035 \mathrm{Nb}, 0.035 \mathrm{Ti}$, and the balance $\mathrm{Fe}$ was annealed at $700^{\circ} \mathrm{C}$ for $1 \mathrm{~h}$, followed by immediate water quenching, to obtain CG austenite samples with average grain size of $20 \mu \mathrm{m}$ (Figure 1(a)). Disks 3-mm thick were sliced from the CG samples and processed by surface mechanical attrition treatment (SMAT) [13,37] for 10-20 min on both surfaces of the disks to produce gradient structures. For comparison, homogeneous samples were processed by cold rolling (CR) the CG samples with thickness reduction of $20 \%, 30 \%$, and $70 \%$, which produces different yield strengths.

Microhardness along the depth for a sample processed by SMAT for $20 \mathrm{~min}$ is shown in Figure 1(b). The sample consists of a $1.5 \mathrm{~mm}$ CG core, sandwiched between two $0.6 \mathrm{~mm}$ gradient layers. The microhardness is about $355 \mathrm{Hv}$ in the core and $600 \mathrm{Hv}$ near the surface. The hardness decreases almost linearly along the depth, which is different from the gradient structure in IF steel [13]. The electron back-scattered diffraction images for the treated surface and the center part are displayed in Figure 1(c, d), which show that the grains at the treated surface are not refined and their sizes are comparable to those in the center part (about $20 \mu \mathrm{m}$ ), while very small sub-grain structures are formed at the treated surface. Transmission electron microscope micrograph in Figure 1(e) reveals these sub-grain structures as parallel deformation twins along two $\{111\}$ planes (primary twins and secondary twins) with inter-twin spacing of $100-300 \mathrm{~nm}$, and intersecting each other. High density of dislocations are also observed in the interior of grains, especially near the twin boundaries. The high microhardness in the surface layer can be attributed to the reduction of the dislocation mean free path by intersecting twins [7] and dislocation entanglements. X-ray diffraction analysis did not detect any phase transformation from the SMAT process (Figure 1(f)).

The set-up of Hopkinson bar experiments, the geometry and dimensions of the hat-shaped specimens and the specimen holders are displayed in Figure $1(\mathrm{~g})$. The extraction of samples for microstructure observations are illustrated in Figure 1(h). Hat-shaped Hopkinson bar experiments have been widely used to study ASB in metals and alloys $[25,26,30-32,34,35]$. Strong cylindrical maraging steel specimen holders were used to ensure 

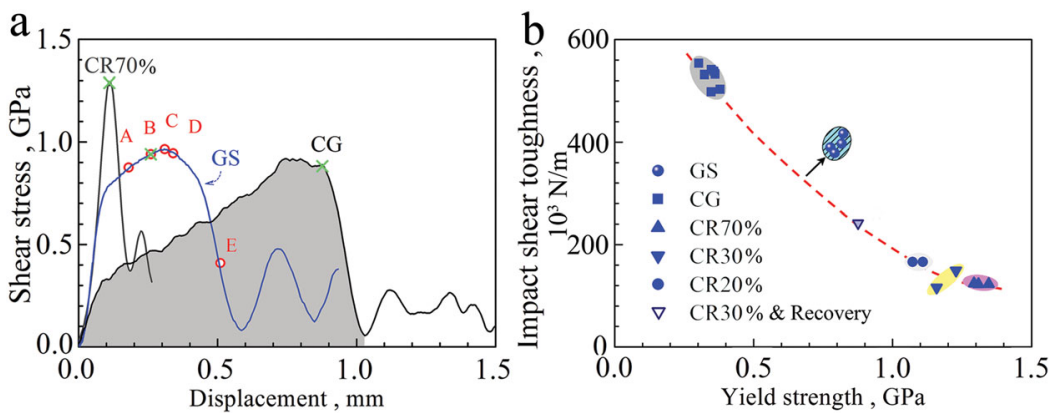

Figure 2. (a) Shear stress vs. shear displacement curves of various samples; (b) impact shear toughness vs. dynamic shear yield strength of the TWIP steel samples with different microstructures. The ASB initiation points are marked as ' $x$ ' in Figure 2(a).

an approximate pure shear deformation by constraining the lateral expansion of two legs for the hat-shaped specimens and to freeze the microstructure at specific shear displacements by varying the height of the specimen holders. Other experimental details can be found in $[25,26,34]$. The impact velocity is around $20 \mathrm{~m} / \mathrm{s}$ for all experiments, and the resultant shear strain rate is around $6 \times 10^{4} / \mathrm{s}$.

The dynamic shear properties for the gradient, CG, and deformed samples (one sample was annealed at $500^{\circ} \mathrm{C}$ for $1 \mathrm{~h}$ ) are shown in Figure 2. The shear stress-shear displacement curves are shown in Figure 2(a). The deformed sample with 70\% thickness reduction has a dynamic shear yield strength of $1300 \mathrm{MPa}$, but stress drops quickly after yielding. The maximum stress point is considered as the initiation point of the strain localization according to the conventional maximum stress criterion for homogeneous materials [25-30], after which ASB begins to form and propagate. Thus, the uniform dynamic plastic shear strain after yielding for this sample is almost zero, indicating a very low strain hardening capability under dynamic shear loading. In contrast, a two-stage dynamic shear flow behavior is visible for the CG sample before the stress drop: a strong linear strain hardening stage followed by a short plateau stage. The CG structure has a low dynamic shear yield strength $(\sim 320 \mathrm{MPa})$, with a very high uniform shear strain of $\sim 4.5$.

The dynamic shear toughness can be calculated from the area under the shear stress-shear displacement curves in Figure 2(a), which is an important parameter for structural components serving under dynamic loading. As shown in Figure 2(b), the strength and dynamic shear toughness of homogeneous materials shows a
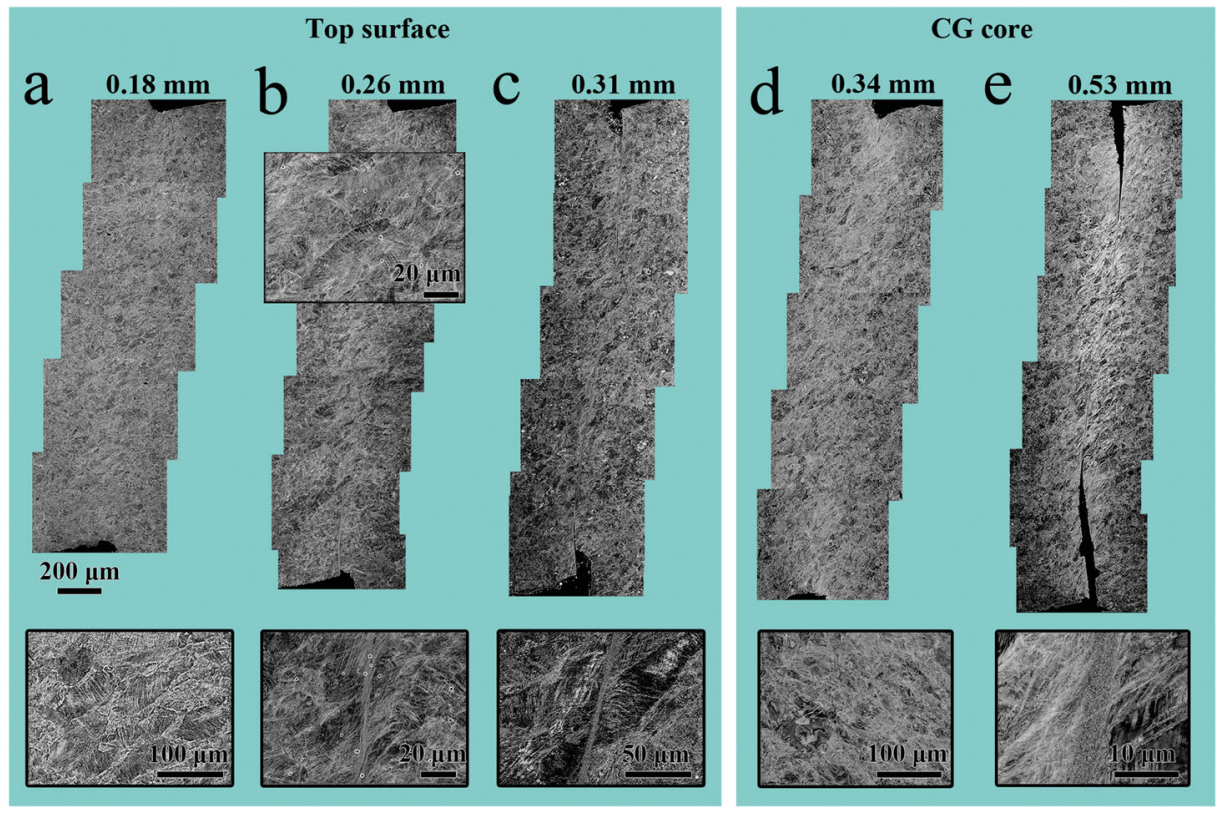

Figure 3. SEM micrographs under BSE mode for the microstructural evolution of the NS surface of a gradient-structured sample at shear displacements of (a) 0.18 , (b) 0.26 , (c) $0.31 \mathrm{~mm}$. SEM micrographs under BSE mode for the microstructural evolution of the CG center of a gradient-structured sample at shear displacements of (d) $0.34 \mathrm{~mm},(e) 0.53 \mathrm{~mm}$. 
typical trade-off. In contrast, the gradient structures show an excellent combination of strength and impact dynamic toughness that is out of reach of homogeneous structure (CG sample and deformed samples with various CR thickness reductions). The dynamic properties might be further optimized by optimizing the gradient structure [19].

In order to understand the corresponding deformation mechanisms under the dynamic shear loading for the gradient structures, dynamic shear experiments with controlled shear deformation at five different interrupted displacements $(0.18,0.26,0.31,0.35,0.53 \mathrm{~mm})$, as marked as 'A, B, C, D, E' in the curve of Figure 2(a), were conducted on samples processed by SMAT for $20 \mathrm{~min}$ to investigate the microstructural evolution. Figure $3(a-c)$ shows the SEM micrographs taken under back-scattered electron mode for the microstructural evolution of the treated surface at the three different interrupted shear displacements. The hat is on the top, and the base ends of hat-shaped specimens are at the bottom. As shown, although the grains are severely sheared, shear band did not form at the shear displacements smaller than $0.26 \mathrm{~mm}$. ASB started to form at the shear displacement of $0.26 \mathrm{~mm}$ and propagated across the whole shear zone for the treated surface at the shear displacement of $0.31 \mathrm{~mm}$.

The microhardness of the homogeneously deformed sample with $70 \%$ CR thickness reduction is about $600 \mathrm{Hv}$, which is close to the surface microhardness of the gradient-structured sample. However, as shown in Figure 2(a), ASB formed right after yielding in this sample basing on the maximum stress criterion for homogeneous materials [25-30]. This is much lower than the ASB onset shear displacement $(0.26 \mathrm{~mm})$ at the surface of the gradient-structured sample. The delayed initiation of ASB in the NS surface layer under dynamic shear loading could also be attributed to the strain gradients and the strain partitioning $[10,12,13,17]$, the interaction between different layers, and the strong strain hardening for the CG center.

Figure 3(d, e) shows the SEM micrographs of the microstructural evolutions of the CG center at two different shear displacements $(0.34,0.53 \mathrm{~mm})$. The shear band is not formed at the shear displacement of $0.34 \mathrm{~mm}$, while a thin shear band is clearly observed at the shear displacement of $0.53 \mathrm{~mm}$. Thus, the critical shear displacement for the initiation of ASB at the CG center is larger than that of the NS surface layer. This is due to the fact that the CG center has much higher strain hardening capability for preserving longer uniform shear deformation than the NS surface layer. This also indicates that ASB first nucleated in the nanostructrued surface and then propagated to the CG center.
In order to probe the physical reason for the observed ASB nucleation at the NS surface layer, we polished away half of the original gradient-structured sample so that one sample surface is NS while the other surface is coarse grained. The dynamic shear test on this new sample was interrupted at the shear displacement of $0.34 \mathrm{~mm}$ for scanning electron microscope (SEM) observation. As shown in Figure 4, ASB nucleated in the NS surface but not in the CG surface at this shear displacement. This indicates that the initiation of ASB at the NS layer was caused by the nanostructure.

In order to probe the ASB propagation from the NS surface to the center, the cross-section along the depth in the concentrated shear zone was examined, and the images at three shear displacements $(0.31,0.34$ and $0.53 \mathrm{~mm}$ ) are displayed in Figure 5. It is well known that once an ASB is initiated in a specific location in homogeneous materials, it can propagate with a speed determined by a number of material parameters and the applied shear impact velocity [38-40]. The propagation

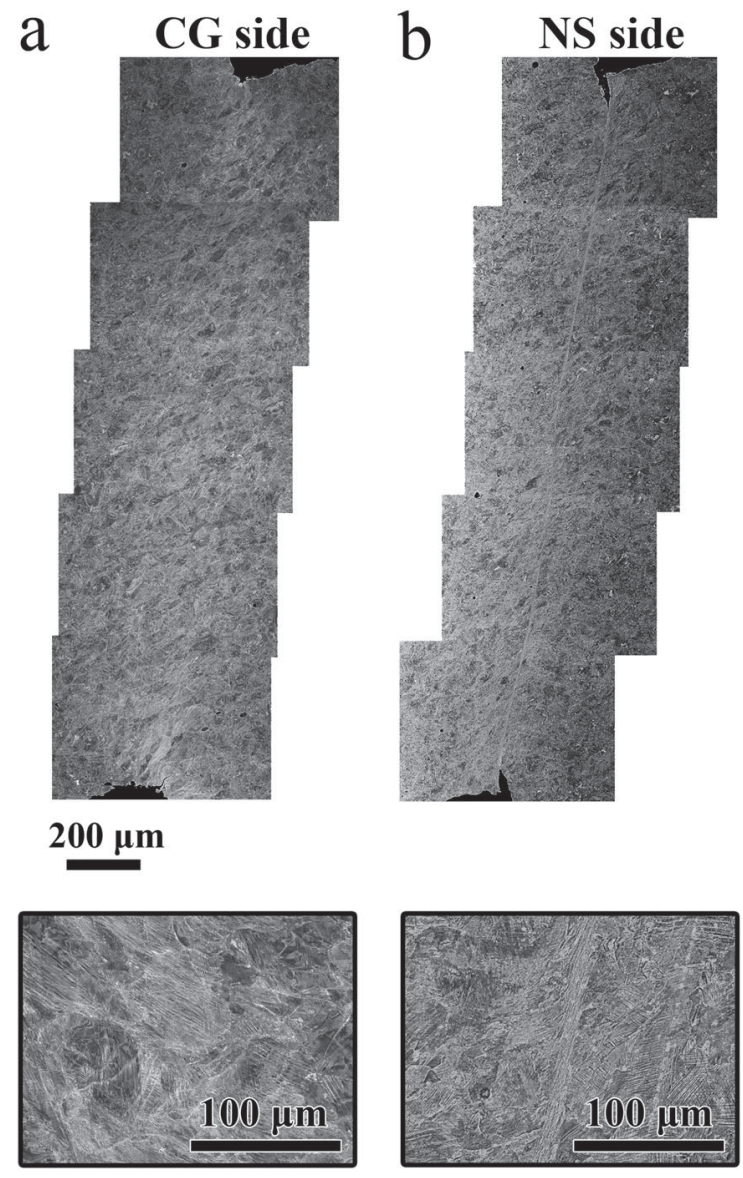

Figure 4. SEM micrograph under BSE mode for the microstructure of a sample with SMAT-produced nanostructure on one side and CG on the other side at the shear displacement of $0.34 \mathrm{~mm}$ : (a) the NS surface side; (b) the CG surface side. 

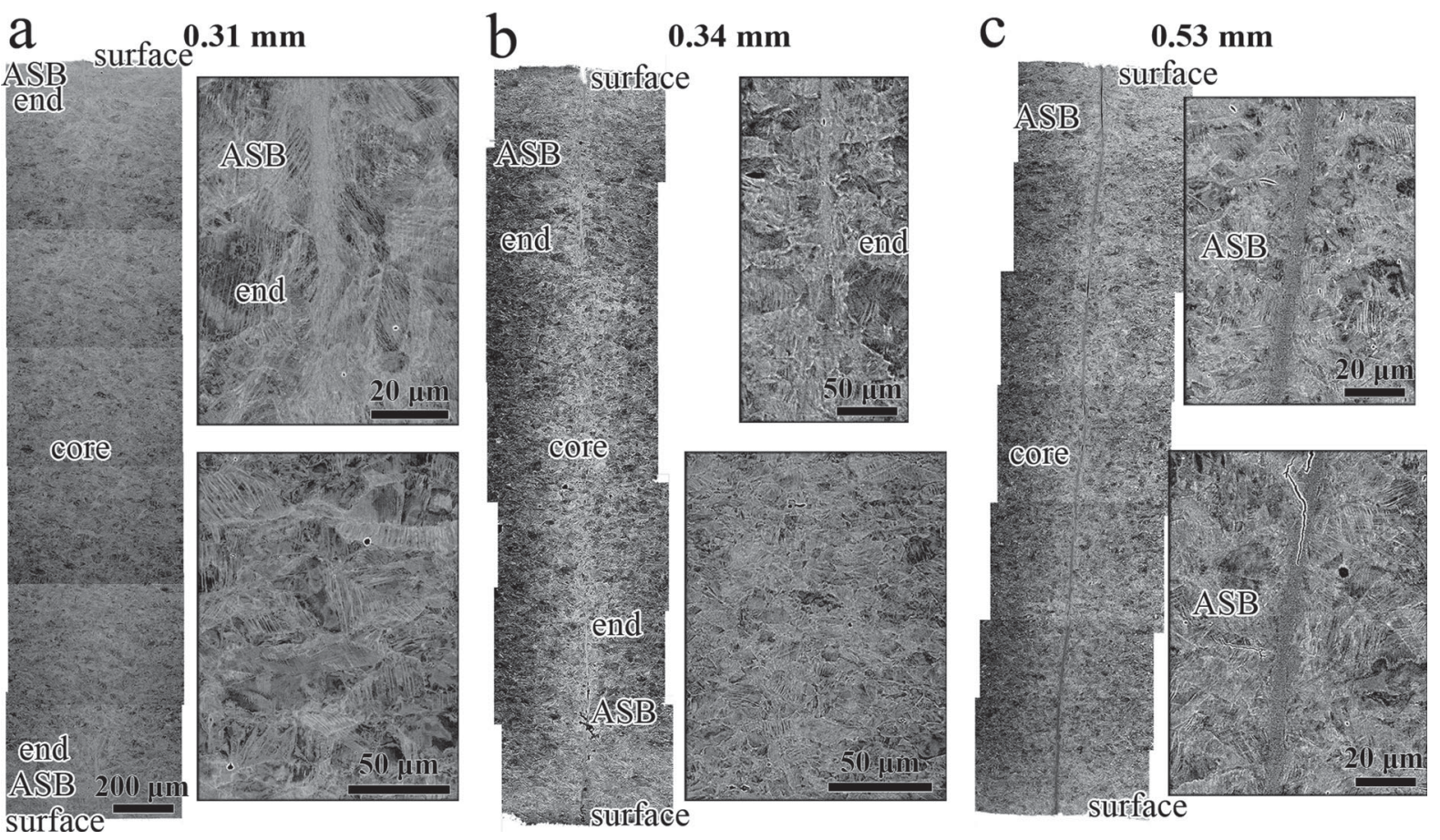

Figure 5. SEM micrographs under BSE mode for the microstructural evolution of the cross-section at three different interrupted shear displacements: (a) $0.31 \mathrm{~mm}$, (b) $0.34 \mathrm{~mm}$, and (c) $0.53 \mathrm{~mm}$.

speed was estimated to be about $600 \mathrm{~m} / \mathrm{s}$ for a CRS 1018 steel when the applied shear impact velocity is about $20 \mathrm{~m} / \mathrm{s}$ (similar to the shear impact velocity applied in the present study) [39]. Two ASBs nucleated at the shear displacement of 0.26 (at the time of about $51 \mu$ s after impact) on the two NS surfaces. At the shear displacement of $0.31 \mathrm{~mm}$ (at the time of about $55 \mu$ after impact), two ASBs propagated for a distance about $0.2 \mathrm{~mm}$ from the two surfaces towards the center. The ASB propagated another $0.3 \mathrm{~mm}$ when the shear displacement increased to $0.34 \mathrm{~mm}$ (at the time of about $59 \mu \mathrm{s}$ after impact). The two ASB tips joined coalesced when the shear displacement increases to $0.53 \mathrm{~mm}$, forming a large ASB across the whole sample thickness. The propagation speed of the ASBs along the thickness in the gradient structures can be estimated by dividing the propagation distance by the time interval, which is about $60 \mathrm{~m} / \mathrm{s}$ and is an order of magnitude slower than that in the homogeneous materials $[38,39]$. This could be attributed to the strain gradients and the strain partitioning $[10,12,13,17]$, the interaction between different layers, and the strong strain hardening for the CG center.

Moreover, the maximum stress criterion in which the shear stress should start to drop once ASB is initiated in the homogeneous materials [25-30] is no longer applicable to gradient structures. As indicated from Figures 2 and 3, the ASB nucleated on the NS surface at the shear displacement of $0.26 \mathrm{~mm}$, while the shear stress did not start to drop until a larger shear displacement of $0.31 \mathrm{~mm}$. The gradient structures can be considered as consisting of numerous thin layers with systematically varying grain sizes/substructure sizes. Therefore, their global average dynamic shear flow stress should be at least the sum of the shear flow stress of different layers [17], as calculated using the rule of mixture (ROM), and might be even higher than what is calculated by ROM due to synergetic extra strengthening caused by the strain gradient associated with the gradient structure, which need to be accommodated by geometrically necessary dislocations (GNDs) and consequently produces back stress hardening $[12,13,17]$.

When the shear displacement is in between 0.26 and $0.31 \mathrm{~mm}$, the NS surface layer is under strain softening due to the formation of ASB, while the CG center is still under strain hardening due to the absence of ASB and the high strain hardening capability of the CG structure. The competition between the softening of surface layers and the hardening of center layers would determine the trend of the flow stress of the overall gradient structures with increasing applied shear displacement. At the early stage of ASB propagation from the surface to the center, the overall flow stress of the gradient structures can still increase with increasing shear displacement. However, when ASB propagates toward the center layers, the fraction of strain softening part would increase. The overall flow stress would start to drop with increasing shear 
displacement at a critical shear displacement. Apparently, this critical shear displacement should be larger than that for onset of ASB at the NS surface layer, making the wellknown maximum stress criterion invalid for gradient structures.

In summary, the gradient TWIP steels behave very differently from the homogeneous counterparts under dynamic loading. It has a combination of strength and dynamic shear toughness that is not accessible to their homogeneous counterparts. The gradient structure delayed the initiation of ASBs on the NS surface and dramatically slowed down the ASB propagation by an order of magnitude, which renders the gradient structure higher in dynamic shear toughness. The superior dynamic properties of the gradient structure are derived from its strain gradient during dynamic shear deformation, which produces GNDs and strong back stress hardening $[10,12,13,17]$. Our findings here provide insights for designing strong and tough metals and alloys for dynamic applications.

\section{Disclosure statement}

No potential conflict of interest was reported by the authors.

\section{Funding}

This work was supported by the National Natural Science Foundation of China (NSFC) [grant number 11472286], [grant number 11572328], and [grant number 11672313]; the Strategic Priority Research Program of the Chinese Academy of Sciences [grant number XDB22040503]; and the National Key Basic Research Program of China [grant number 2012CB932203] and [grant number 2012CB937500]. Y.Z. was supported by the US Army Research Office [grant number W911 NF-12-1-0009], and the Nanjing University of Science and Technology.

\section{References}

[1] Youssef KM, Scattergood RO, Murty KL, et al. Ultrahigh strength and high ductility of bulk nanocrystalline copper. Appl Phys Lett. 2005;87(9):091904.

[2] Zhu YT, Liao XZ. Nanostructured metals-retaining ductility. Nat Mater. 2004;3(6):351-352.

[3] Meyers MA, Mishra A, Benson DJ. Mechanical properties of nanocrystalline materials. Prog Mater Sci. 2006;51(4):427-556.

[4] Wang YM, Chen MW, Zhou FH, et al. High tensile ductility in a nanostructured metal. Nature. 2002;419(6910): 912-915.

[5] Zhao YH, Liao XZ, Cheng S, et al. Simultaneously increasing the ductility and strength of nanostructured alloys. Adv Mater. 2006;18(17):2280-2283.

[6] Lu L, Chen X, Huang X, et al. Revealing the maximum strength in nanotwinned copper. Science. 2009;323(5914): 607-610.
[7] Kou HN, Lu J, Li Y. High-strength and high-ductility nanostructured and amorphous metallic materials. Adv Mater. 2014;26:5518-5524.

[8] Liddicoat PV, Liao XZ, Zhao YH, et al. Nanostructural hierarchy increases the strength of aluminium alloys. Nat Commun. 2010;1:63.

[9] Liu G, Zhang GJ, Jiang F, et al. Nanostructured highstrength molybdenum alloys with unprecedented tensile ductility. Nat Mater. 2013;12:344-350.

[10] Wu XL, Yang MX, Yuan FP, et al. Heterogeneous lamella structure unites ultrafine grain strength with coarsegrain ductility. Proc Natl Acad Sci USA. 2015;112(47): 14501-14505.

[11] Valiev RZ. Nanostructuring of metals by severe plastic deformation for advanced properties. Nat Mater. 2004;3:511-516.

[12] Yang MX, Pan Y, Yuan FP, et al. Back stress strengthening and strain hardening in gradient structure. Mater Res Lett. 2016;4(3):141-151.

[13] Wu XL, Jiang P, Chen L, et al. Extraordinary strain hardening by gradient structure. Proc Natl Acad Sci USA. 2014;111(20):7197-7201.

[14] Suresh S. Graded materials for resistance to contact deformation and damage. Science. 2001;292(5526): 2447-2451.

[15] Fang TH, Li WL, Tao NR, et al. Revealing extraordinary intrinsic tensile plasticity in gradient nano-grained copper. Science. 2011;331(6024):1587-1590.

[16] Wei YJ, Li YQ, Zhu LC, et al. Evading the strengthductility trade-off dilemma in steel through gradient hierarchical nanotwins. Nat Commun. 2014;5:3580.

[17] Wu XL, Jiang P, Chen L, et al. Synergetic strengthening by gradient structure. Mater Res Lett. 2014;2(4): $185-191$.

[18] Hughes DA, Hansen N. Graded nano-structures produced by sliding and exhibiting universal behavior. Phys Rev Lett. 2001;87(13):135503.

[19] Zeng Z, Li XY, Xu DS, et al. Gradient plasticity in gradient nano-grained metals. Extreme Mech Lett. 2015;8: 213-219.

[20] Feaugas X. On the origin of the tensile flow stress in the stainless steel AISI 316L at $300 \mathrm{~K}$ : back stress and effective stress. Acta Mater. 1999;47(13):3617-3632.

[21] Ashby MF. The deformation of plastically nonhomogeneous materials. Philos Mag. 1970;21(170):399-424.

[22] Zener C, Hollomon JH. Effect of strain rate upon plastic flow of steel. J Appl Phys. 1944;15:22-32.

[23] Nemat-Nasser S, Guo WG. Thermomechanical response of DH-36 structural steel over a wide range of strain rates and temperatures. Mech Mater. 2003;35:10231047.

[24] Suo T, Li YL, Zhao F, et al. Compressive behavior and rate-controlling mechanisms of ultrafine grained copper over wide temperature and strain rate ranges. Mech Mater. 2013;61:1-10.

[25] Mishra A, Martin M, Thadhani NN, et al. High-strain rate response of ultra-fine-grained copper. Acta Mater. 2008;56:2770-2783.

[26] Yuan FP, Bian XD, Jiang P, et al. Dynamic shear response and evolution mechanisms of adiabatic shear band in an ultrafine-grained austenite-ferrite duplex steel. Mech Mater. 2015;89:47-58. 
[27] Meyers MA, Subhash G, Kad BK, et al. Evolution of microstructure and shear-band formation in $\alpha$-hcp titanium. Mech Mater. 1994;17:175-193.

[28] Bai Y, Dodd B. Adiabatic shear localization. New York (NY): Pergamon Press; 1992.

[29] Wright TW. The physics and mathematics of adiabatic shear bands. Cambridge: Cambridge University Press; 2002.

[30] Xue Q, Gray III GT, Henrie BL, et al. Influence of shock prestraining on the formation of shear localization in 304 stainless steel. Metall Mater Trans A. 2005;36A:1471-1486.

[31] Yang Y, Jiang F, Zhou BM, et al. Influence of shock prestraining on the formation of shear localization in 304 stainless steel. Mater Sci Eng A. 2011;528:27872794.

[32] Yuan FP, Jiang P, Wu XL. Annealing effect on the evolution of adiabatic shear band under dynamic shear loading in ultra-finegrained iron. Int J Impact Eng. 2012;50: $1-8$.

[33] Wei Q, Kecskes L, Jiao T, et al. Adiabatic shear banding in ultrafine-grained $\mathrm{Fe}$ processed by severe plastic deformation. Acta Mater. 2004;52:1859-1869.
[34] Xing JX, Yuan FP, Wu XL. Enhanced quasi-static and dynamic shear properties by heterogeneous gradient and lamella structures in 301 stainless steels. Mater Sci Eng A. 2017;680:305-316.

[35] Johansson J, Persson C, Lai HP, et al. Microstructural examination of shear localisation during high strain rate deformation of alloy 718. Mater Sci Eng A. 2016;662:363-372.

[36] Sun JL, Trimby PW, Yan FK, et al. Shear banding in commercial pure titanium deformed by dynamic compression. Acta Mater. 2014;79:47-58.

[37] Lu K, Lu J. Surface nanocrystallization (SNC) of metallic materials-presentation of the concept behind a new approach. J Mater Sci Technol. 1999;15:193-197.

[38] Xue, Q, Meyers, MA. Self-organization of shear bands in titanium and Ti-6Al-4V alloy. Acta Mater. 2002;50: 575-596.

[39] Bonnet-Lebouvier, AS, Molinari, A, Lipinski, P. Analysis of the dynamic propagation of adiabatic shear bands. Inter J Solids Struct. 2002;39:4249-4269.

[40] Guduru, PR, Rosakis, AJ, Ravichandran, G. Dynamic shear bands: an investigation using high speed optical and infrared diagnostics. Mech Mater. 2001;33:371-402. 